\title{
USING UV LASER SURFACE TREATMENT TO MODIFY THE WETTABILITY CHARACTERISTICS OF POLYAMIDE 6,6 AND ITS EFFECTS ON OSTEOBLAST CELL ACTIVITY.
}

\author{
Paper (Paper Number)
}

\author{
David G. Waugh ${ }^{1}$ and Jonathan Lawrence ${ }^{2}$ \\ ${ }^{1}$ Wolfson School of Mechanical and Manufacturing Engineering, Loughborough University, \\ Loughborough, LE11 3TU, UK \\ ${ }^{2}$ The Automotive Company, Address, City, State, Postal Code, Country
}

\begin{abstract}
Lasers can be used to modify the surface characteristics of a number of different materials for many applications. This paper details the way in which a $\mathrm{KrF} 248 \mathrm{~nm}$ excimer laser can be utilized to surface pattern and whole area irradiate nylon 6,6. 50 and 100 $\mu \mathrm{m}$ dimensioned trench and hatch patterns were induced in addition to the whole area irradiative processing which covered an area of $3.75 \mathrm{~cm}^{2}$ with fluencies ranging from 26 to $70 \mathrm{mJcm}^{-2}$. The surface topography and roughness were determined with the use of a white light interferometer. From this it was found that the largest roughness, $\mathrm{Sa}$, was $1.53 \mu \mathrm{m}$ which arose from the $100 \mu \mathrm{m}$ hatch excimer patterned sample. Wettability characteristics were obtained for each sample using a sessile drop device in which it was observed that the contact angle increased by up to $25^{\circ}$ for the patterned samples and decreased by up to $15^{\circ}$ for the large area processed samples. It is believed that the observed increase in contact angle can be attributed to the likely existence of a mixed-state wetting regime in which both Wenzel and Cassie-Baxter regimes are present over the liquid-solid interface. As a result of the small variation in surface roughness for the large area processed samples the observed decrease in contact angle can be explained by a modification of the surface chemistry and an increase in polar component $\left(\gamma^{\mathrm{p}}\right)$ and total surface energy $\left(\gamma^{\mathrm{T}}\right)$. Osteoblast cell activity was analyzed by carrying out cytotoxicity and alkaline leukocyte phosphatase (ALP) activity experiments, two major factors which are linked to sufficient cell growth and proliferation.
\end{abstract}

\section{Introduction}

Cytotoxicity is usually evaluated by the quantification of plasma membrane damage due to the fact that upon damage of the plasma membrane, lactate dehydrogenase (LDH) is rapidly released into the cell culture medium. As a result of this, LDH is the most common and widely used marker in cytotoxicity studies. Thus it can be seen that due to the significance of cytotoxicity in determining the cell response of biomaterials a number of studies have been carried out using various materials [1-4]. By carrying out this study it allows one to determine the quality of the cells produced. It could also be used to determine if a specific biomaterial surface gives rise to better quality cell growth.

Alkaline leukocyte phosphatase (ALP) activity is involved in bone formation and has been shown that ALP is significant in the development of skeletal calcification [5]. With regards to bone formation, it is believed that ALP acts at the focal site of bone creation by eradicating inorganic pyrophosphate which is known to potentially inhibit calcification [5]. As a result of this, experimentation has been carried out to detect the ALP activity in order to assess the biofunctionality of biomaterials [1].

Owed to insufficient biomimetic surface properties [1] a number of techniques have been implemented for surface treatment [6-8]. Lasers offer major advantages over alternative techniques for materials processing. Some of the main advantages of using a laser for materials processing are accurate, precise, non-contact processing with automation (repeatability) of the various processing techniques being relatively easy to implement.

On account of lasers offering a convenient means of surface treatment this paper details, for the first time, unique experimentation into using $\mathrm{CO}_{2}$ lasers for patterning and whole area irradiative processing of nylon 6,6 and the effects this had on the wettability characteristics, cytotoxicity and alkaline leukocyte phosphatase (ALP) activity. What is more, the possible effect of wettability characteristics on osteoblast cell response is discussed in terms of resulting cytotoxicity and ALP levels. 


\section{Experimental Technique}

Material

The nylon 6,6 was sourced in $100 \times 100 \mathrm{~mm}^{2}$ sheets with a thickness of $5 \mathrm{~mm}$ (Goodfellow Cambridge, Ltd). To obtain a conveniently sized sample for experimentation the as-received nylon sheet was cut into $30 \mathrm{~mm}$ diameter discs using a $1 \mathrm{~kW}$ continuous wave (cw) $\mathrm{CO}_{2}$ laser (Everlase S48; Coherent, Ltd).

\section{Laser-Induced Patterning}

For the patterned experiments the repetition rate was kept constant at $25 \mathrm{~Hz}$, with a number of 10 pulses per site and used Aerotech CNC programming to induce the required pattern. A constant laser energy of $80 \pm 7$ $\mathrm{mJ}$ was used with the attenuator set to $0.3(30 \%)$ giving a measured energy at the target sample of $23.67 \pm 2.5 \mathrm{~mJ}$, resulting in a fluence of $858 \pm 91$ $\mathrm{mJ} / \mathrm{cm}^{2}$. In order to induce the intended pattern a projection imaging system was implemented with a focusing lens of $\times 10$ demagnification. The patterns induced using this technique were $50 \mu \mathrm{m}$ trench (ET50), $100 \mu \mathrm{m}$ trench (ET100), $50 \mu \mathrm{m}$ hatch (EH50) and $100 \mu \mathrm{m}$ (EH100). Two non-contact masks were used for both dimensioned patterns which included a brass mask with six $1 \mathrm{~mm}$ diameter holes spaced by 2 $\mathrm{mm}$, centre to centre, for the $100 \mu \mathrm{m}$ dimensions and a SS316 foil (Laser Micromachining Ltd., UK) with five $0.5 \mathrm{~mm}$ diameter holes spaced by $1.5 \mathrm{~mm}$, 'centre to centre', for the $50 \mu \mathrm{m}$ dimensions (see Figure 5.3). To keep the constant 10 pulses per site scanning velocities of $0.125 \mathrm{mms}^{-1}$ and $0.25 \mathrm{mms}^{-1}$ were used for the 50 $\mu \mathrm{m}$ and $100 \mu \mathrm{m}$ dimensioned patterns, respectively.

\section{Whole Area Irradiative Processing}

For the whole area processing with an excimer laser the raw $23 \times 12 \mathrm{~mm}^{2}$ beam was used to irradiate a large section of each sample at a time. In order to hold the sample normal to the beam a bracket on the optical train was used. For the large area processing experiments 6 samples where studied; these being 100 pulses at $100 \mathrm{~mJ}$ (EWA100), 100 pulses at $150 \mathrm{~mJ}$ (EWA150), 100 pulses at $200 \mathrm{~mJ}$ (EWA200), 100 pulses at $250 \mathrm{~mJ}$ (EWA250), 500 pulses at $250 \mathrm{~mJ}$ (EWA250_500) and 1000 pulses at $250 \mathrm{~mJ}$ (EWA250_1000). This gave fluences of $36 \pm 3,54 \pm 5$, $72 \pm 8$ and $\overline{9} \pm 10 \mathrm{~mJ} / \mathrm{cm} 2$, respectively for the different energies used. Throughout the whole area excimer experiments the repetition rate was kept constant at 25 $\mathrm{Hz}$ and Aerotech $\mathrm{CNC}$ programming ensured that the correct number of pulses was applied to each sample.
For both laser processing types a set of samples for four 6-well plates were produced; named plate 1, 2, 3 and 4.

\section{Topography, Wettability Characteristics and Surface Chemistry Analysis}

The surface roughness parameters, $\mathrm{Sa}$ and $\mathrm{Ra}$, were determined using a white light interferometer (WLI) (NewView 500; Zygo, Ltd) with MetroPro and TalyMap Gold Software. The Zygo WLI was setup using a $\times 10$ Mirau lens with a zoom of $\times 0.5$ and working distance of $7.6 \mathrm{~mm}$.

In accordance with Rance [9] the samples from plate 1 were ultrasonically cleaned in isoproponal (Fisher Scientific Ltd., UK) for 3 minutes at room temperature. A sessile drop device (OCA20; Dataphysics Instruments, $\mathrm{GmbH}$ ) was used with relevant software (SCA20; Dataphysics Intrsuments, $\mathrm{GmbH}$ ) to allow the recent advancing for triply distilled water and for diodomethane to be determined for each sample. Thereafter the advancing contact angles for the two liquids were used by the software to draw an Owens, Wendt, Rabel and Kaeble (OWRK) plot to determine the surface energy of the samples. For the two reference liquids the SCA20 software used the Ström et al. technique to calculate the surface energy of the material. It should be noted here that ten contact angles, using two droplets, in each instance was recorded to achieve a mean contact angle for each liquid and surface.

All samples were analysed using x-ray photoelectron spectroscopy (XPS) analysis. This allowed any surface modifications in terms of surface oxygen content due to the laser irradiation to be revealed.

\section{Osteoblast Cell Response, Cytotoxicity and Alkaline Leukocyte Phosphatase Activity (ALP) In Vitro Experimentation}

Prior to any biological testing being carried out the samples were autoclaved (D-Series Bench-Top Autoclave; Systec, $\mathrm{GmbH}$ ) to ensure that all samples were sterilized. For all biological work undertaken, unless stated, a biological safety cabinet (BSC) (Microflow Class II ABS Cabinet; BioQuell UK, Ltd) was used to provide a clean, sterile environment.

Normal human oteoblast cells (Clonetics CC-2538; Lonza, Inc.) were initially cultured in a T75 (75ml) flask by suspending the cells in $19 \mathrm{ml}$ culture medium comprising of $90 \%$ eagle minimum essential medium (Sigma-Aldrich, UK) and 10\% foetal bovine serum (FBS) (Sigma-Aldrich, UK). The flask was then placed in an incubator and left for 24 hours. After 24 hours 
the cells were assessed and the spent media was aspirated before dispensing $15 \mathrm{ml}$ of fresh media and returning the flask to the incubator for 3 days.

The period of 3 days allowed the cells to become confluent. The cells were detached from the flask using $5 \mathrm{ml}$ Trypisn-EDTA (Sigma-Aldrich, UK) whilst placed in the incubator for seven minutes. Once all cells had become detached $10 \mathrm{ml}$ culture medium was added to neutralize the Trypsin. In order to aspirate the supernatant the cell culture was centrifuged (U-320R; Boeco, GmbH) for five minutes at $200 \mathrm{~g}$. the cells were then dispensed between the eighteen samples in the 6 -well plates with $0.55 \mathrm{ml}\left(2 \times 10^{4}\right.$ cells $\left./ \mathrm{ml}\right)$. Three 6 -well plates were prepared. Plate 2 was analysed using SEM after 24 hours which required the samples to be initially rinsed with phosphate-buffered saline (PBS) (Sigma-Aldrich, UK) to remove any unattached cells. Then, adherent cells were fixed using $1.2 \%$ glutaraldehyde in water (Sigma-Aldrich, UK) at room temperature for 1 hour within the BSC before using a graded series of ethanol/distilled water mixtures of 50/50, 80/20, 90/10, 95/5, 98/2 and 100/0. Each sample was left in these mixtures for 10 minutes to ensure dehydration. Once this procedure was carried out the samples were mounted and sputter coated with $\mathrm{Au}$ so that SEM images could be obtained. Plate 3 and plate 4 were kept incubated for 2 days by which time the media for each sample was removed to assess both the cytotoxicity and ALP levels.

In order to determine the cytotoxicity and ALP activity of the seeded osteoblast cells in plate 3 and plate 4 after 2 days of incubation an LDH-cytotoxicity assay kit II (313-500; Biovision, Inc.) and a Sensolyte FDP Alkaline Phosphatase Assay Kit (71109; Anaspec, Inc.) were used, respectively. In order to measure the cytotoxicity level for each of the samples a number of controls were setup; background control which had $100 \mu \mathrm{l}$ per well of culture medium without cells, low control which had $100 \mu \mathrm{l}$ per well of culture medium with cells, test substance which had $100 \mu$ per well of culture medium from the nylon 6,6 samples and high control which had $100 \mu \mathrm{l}$ per well of culture medium with cells in addition to $10 \mu \mathrm{l}$ of cell lysis solution. Each of these wells were performed in duplicates, had $100 \mu \mathrm{l}$ of $\mathrm{LDH}$ reaction mix added to them and were incubated at room temperature for 30 minutes prior to measuring the absorbance with a 96-well plate reader. The absorbance was measured with a $450 \mathrm{~nm}$ (440 to $490 \mathrm{~nm}$ ) filter and used a reference wavelength of 650 $\mathrm{nm}$. Using the controls that had been set it was possible to ascertain the \% cytotoxicity by using the following equation: oytotoxietty $(\%)=\frac{(\text { Test sample }- \text { Lew eontrol })}{\text { (High eontrol }- \text { Low eontrol })} \times 100$

(3.1)

ALP activity was determined by setting up three controls; negative control which had $50 \mu \mathrm{l}$ per well of unused culture medium, substrate control which contained $50 \mu \mathrm{l}$ per well of $1 \mathrm{X}$ lysis buffer and the test substrate which had $50 \mu \mathrm{l}$ per well of the culture media from the nylon 6,6 samples. In order to measure the ALP activity $50 \mu \mathrm{l}$ of FDP reaction was added to each well, mixed and incubated at room temperature for 30 minutes. After this time the 96-well plate was placed into a spectrophotometer and the fluorescence intensity was measured at $\mathrm{Ex} / \mathrm{Em}=485 \pm 20 \mathrm{~nm} / 528 \pm 20 \mathrm{~nm}$. It should be noted that for both cytotoxicity and ALP activity the background/substrate control was taken away from all readings to account for background levels.

\section{Results and Discussion}

\section{Wettability Characteristics}

Table 7.3 gives a summary of the surface parameters and wettability characteristics for each of the samples studied. It can be seen that on account of the $\mathrm{KrF}$ excimer laser-induced patterning of the nylon 6,6 samples $\theta$ increased by up to $24^{\circ}$ in comparison to the as-received sample (AR) which had a $\theta$ of $56.4 \pm 1.2^{\circ}$. This does not appear to corroborate with current theory as an increase in surface roughness for a hydrophilic material should bring about a reduction in the $\theta$, as previously discussed in Chapter 6. This increase in $\theta$ arising from the excimer patterned samples can be accounted for by the reduction in apparent polar component, $\gamma^{\mathrm{P}}$, and apparent total surface free energy, $\gamma^{\mathrm{T}}$, which is modified by the liquids equilibrium state. That is, the wetting regime has changed on account of the surface topography. As discussed in Chapter 6 there is a likelihood that this transition in wetting regime is a mixed-state wetting regime in which both Wenzel and Cassie-Baxter regimes form along the liquid-surface interface [10-13]. It should also be noted here that Table 7.3 confirms that as a result of the $\mathrm{KrF}$ excimer laser-material oxidation of the surface was observed, allowing the surface oxygen content to increase by at most $1.6 \%$ at. The largest increase in surface oxygen content was found to be from the hatch patterned samples (EH50 and EH100) owed to the fact that more material was ablated inducing more surface oxidation. 
Table 7.3 - Results summary for all samples showing roughness parameters, surface oxygen content and wettability characteristics for $\mathrm{KrF}$ processed nylon 6,6.

\begin{tabular}{cccccccc}
\hline Sample ID & $\begin{array}{c}\mathrm{Sa} \\
(\mu \mathrm{m})\end{array}$ & $\begin{array}{c}\mathrm{Ra} \\
(\mu \mathrm{m})\end{array}$ & $\begin{array}{c}\gamma^{\mathrm{P}} \\
\left(\mathrm{mJm}^{-2}\right)\end{array}$ & $\begin{array}{c}\gamma^{\mathrm{D}} \\
\left(\mathrm{mJm}^{-2}\right)\end{array}$ & $\begin{array}{c}\gamma^{\mathrm{T}} \\
\left(\mathrm{mJm}^{-2}\right)\end{array}$ & $\begin{array}{c}\text { Surface Oxygen Content } \\
(\% \mathrm{at} .)\end{array}$ & $\begin{array}{c}\text { Contact Angle } \\
\left({ }^{\circ}\right)\end{array}$ \\
\hline AR & 0.126 & 0.029 & 17.69 & 29.66 & 47.34 & 13.26 & $56.4 \pm 1.2$ \\
ET50 & 0.281 & 0.312 & 15.48 & 28.74 & 44.22 & 13.87 & $60.6 \pm 3.0$ \\
ET100 & 1.320 & 0.679 & 6.52 & 23.54 & 30.06 & 13.53 & $80.8 \pm 5.2$ \\
EH50 & 0.739 & 0.548 & 12.94 & 17.24 & 30.17 & 14.15 & $75.1 \pm 3.9$ \\
EH100 & 1.530 & 1.032 & 17.06 & 13.55 & 30.61 & 14.83 & $73.0 \pm 3.7$ \\
EWA100 & 0.119 & 0.029 & 21.72 & 27.08 & 48.79 & 13.11 & $52.8 \pm 1.1$ \\
EWA150 & 0.092 & 0.039 & 25.98 & 24.76 & 50.74 & 13.03 & $49.1 \pm 4.7$ \\
EWA200 & 0.108 & 0.030 & 25.26 & 25.86 & 51.12 & 13.28 & $48.9 \pm 2.6$ \\
EWA250 & 0.107 & 0.031 & 22.37 & 28.66 & 51.03 & 13.24 & $50.3 \pm 1.5$ \\
EWA250_500 & 0.164 & 0.039 & 33.31 & 21.40 & 54.71 & 15.32 & $42.9 \pm 1.6$ \\
EWA250_1000 & 0.198 & 0.036 & 37.56 & 20.89 & 58.46 & 18.36 & $37.6 \pm 3.2$ \\
\hline
\end{tabular}

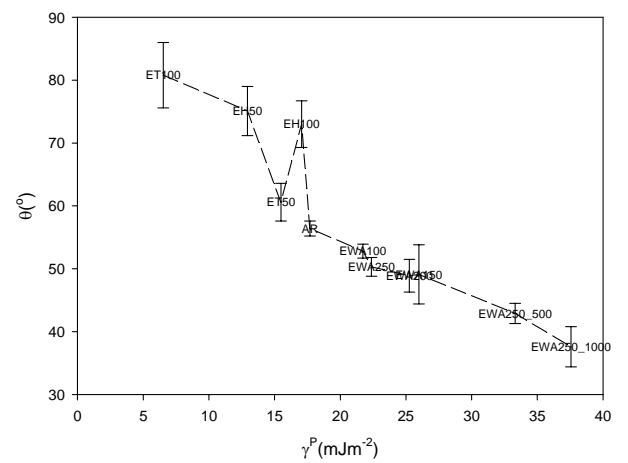

(a)

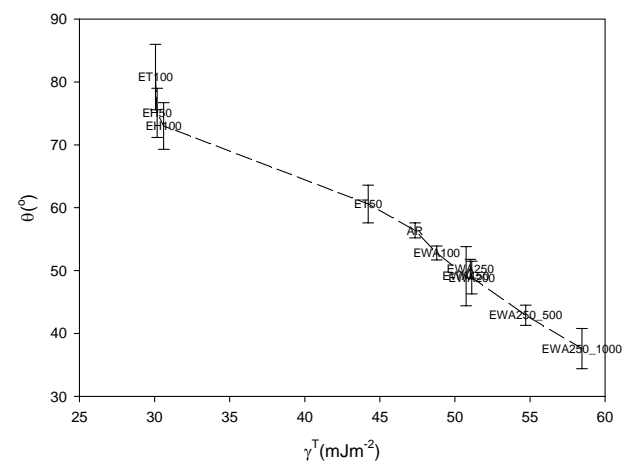

(b)

Figure 7.7 - Graphs showing the correlation between $\theta$ and (a) $\gamma^{\mathrm{P}}$ and (b) $\gamma^{\mathrm{T}}$.

In terms of collating the $\gamma^{\mathrm{P}}$ and $\gamma^{\mathrm{T}}$ results for the entire $\mathrm{KrF}$ excimer laser processed samples and the effects thereof on $\theta$, Figure 7.7 shows that there was a strong inverse function correlation between $\theta$ and the surface energy parameters regardless of the processing technique used. This indicates that $\gamma^{\mathrm{P}}$ and $\gamma^{\mathrm{T}}$ could be the main driving parameters determining the wettability of the nylon 6,6 samples in this instance. As a result it may be possible to use these parameters as indicators of how nylon 6,6 will wet as long as the results are repeatable. Having said that, as discussed in Section 7.3.2, similar values of $\gamma^{\mathrm{P}}$ and $\gamma^{\mathrm{T}}$ give rise to equivalent $\theta$ suggesting that this process is repeatable.

\section{Osteoblast Cell Response: 24 hours}

After $24 \mathrm{hrs}$ incubation time for the osteoblast cell seeded samples it can be seen from the SEM micrographs shown in Figure 12.12 that the cells had begun to adhere and proliferate across each of the $\mathrm{KrF}$ excimer laser-induced patterned nylon 6,6 samples. Similar to the as-received sample (see Figure 11.10) the $\mathrm{KrF}$ excimer laser-induced patterned samples gave rise to osteoblast cells with a bipolar cell morpohology. One major difference between the cell growth on the as-received sample (see Figure 11.10) and the $\mathrm{KrF}$ excimer laser-induced patterned samples is that the excimer patterned nylon 6,6 samples gave rise to some form of directionality; that is, the cells appear to be preferentially growing along the grooves formed by the excimer laser. This could have been induced by the surface roughness and surface oxygen content being higher (see Table 7.3) in the grooves produced allowing for preferential cell growth.

Figure 12.16(a) shows a histogram of the cover density for each of the $\mathrm{KrF}$ excimer laser processed samples seeded with normal human osteoblast cells after $24 \mathrm{hrs}$ incubation. It can be seen that the $\mathrm{KrF}$ excimer laserinduced patterned samples had a cover density of around $20 \%$ which was seen to be equivalent to that seen for the as-received sample (AR). 


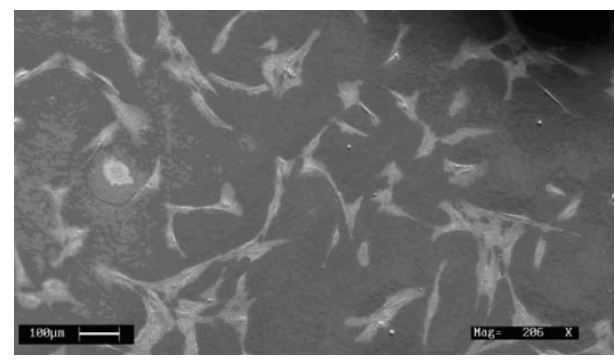

Figure 11.12 - SEM micrograph of Au coated samples $24 \mathrm{hrs}$ post seeding for the as-received sample (AR).

It was also seen from Figure 12.16 that samples WA250_500 and WA250_1000 gave rise to slightly less cover densities of around 17 and $19 \%$, respectively, whereas the largest cover density of $25 \%$ was obtained for the other $\mathrm{KrF}$ excimer laser whole area irradiative processed samples. Figure 12.16(a) also allows one to see that through different excimer laser processes the osteoblast cell response on the nylon 6,6 surfaces, in terms of cell cover density, can be significantly modulated, indicating that $\mathrm{KrF}$ excimer laser processing is an attractive means for enhancing and hindering cell growth dependant on the intended application. It can also be seen that there may have been some correlative trend between $\theta$ and the cell cover density, which will be discussed later.

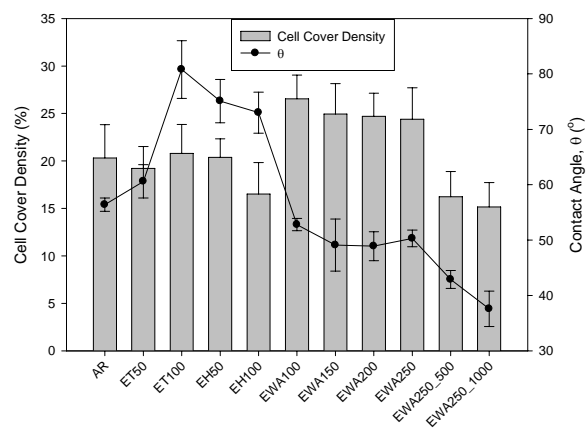

Sample I.D.

Figure 12.16 - (a) Histogram showing the cell cover density in relation to $\theta$ for all $\mathrm{KrF}$ excimer laser processed samples after $24 \mathrm{hrs}$ incubation.

\section{Cytotoxicity and ALP Level}

Figure 12.39(a) and Figure 12.39(b) also show that for the $\mathrm{KrF}$ excimer laser-induced patterned nylon 6,6 samples there did not appear to be any correlation with what was observed for the $\mathrm{KrF}$ excimer laser whole area irradiative processed samples. This can be attributed to the likely transition in wetting regime, discussed in Chapter 10, having a large impact on varying the results obtained. However, by taking the entire $\mathrm{KrF}$ excimer laser processed samples into account, Figure 12.39(b) allows one to see that there appeared to be an optimum window of $\theta$ for the nylon 6,6 between 47 and $55^{\circ}$ which elicited a reduction in cytotoxicity.

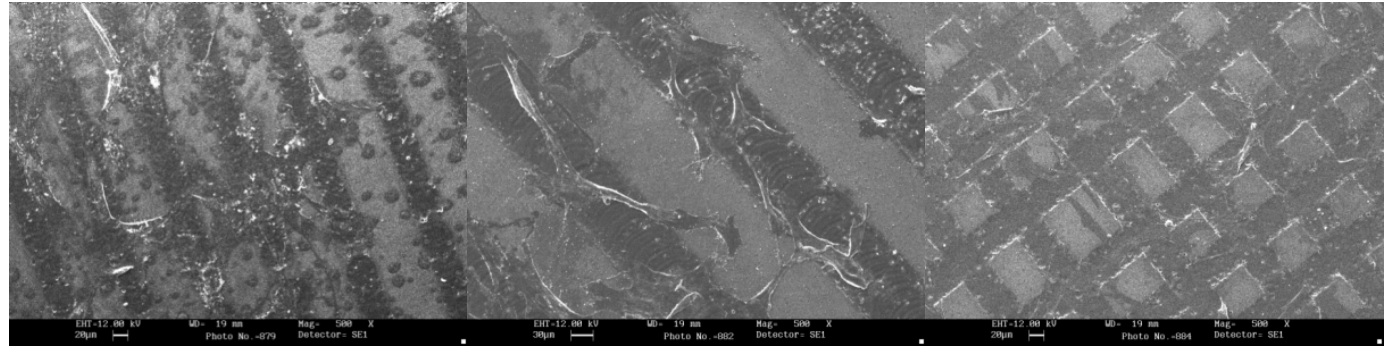

(a) (c) (b)

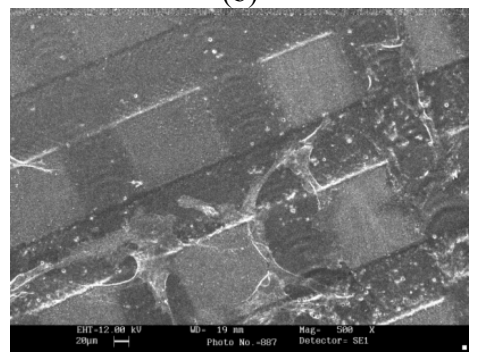

(d)

Figure 12.12 - SEM micrographs of the KrF excimer laser-induced patterned samples (a) ET50, (b) ET100, EH50 and (d) EH100 after 24 hrs incubation. 
With the modulation of the cytotoxicity levels being observed it is possible for one to deduce that the $\mathrm{KrF}$ excimer laser surface treatments would have a similar effect on the ALP levels. Figure 12.40(a) shows a histogram of the ALP levels in relation to $\theta$. It was found from Figure 12.40(a) that sample EWA250_1000 gave rise to the lowest ALP level of 16 RFU which can be attributed to the increase in cytotoxicity and a decrease in $\theta$. In general all of the $\mathrm{KrF}$ excimer laser whole area irradiative processed samples, apart from samples EWA100, EWA150 and EWA200, lead to a reduction in ALP as a result of the increase in cytotoxicity levels. In terms of $\theta$, from Figure 12.40(b) it can be seen that there appears to be a threshold window of between 47 and $55^{\circ}$ for nylon 6,6 which gives rise to an increased ALP level of between 33 and $40 \mathrm{RFU}$. That is, any $\theta$ below or above this threshold results in a hindered ALP response. This gives further evidence to the optimum parameter window proposed earlier for the cytotoxicity (see Figure 12.39).

Figure 11.41(a) shows that in general, for the $\mathrm{KrF}$ excimer laser whole area irradiative processed nylon 6,6 samples, the cytotoxicity increased steadily upon an increase in $\gamma^{\mathrm{P}}$. In contrast, a correlative trend between the cytotoxicity and $\gamma^{\mathrm{P}}$ for the $\mathrm{KrF}$ excimer laser-induced patterned samples was not readily discernible from Figure 11.41(a). Having said that, Figure 11.41(b) does show that the cytotoxicity for all of the $\mathrm{KrF}$ excimer laser processed samples could have had a trend with $\gamma^{\mathrm{P}}$ such that between $\gamma^{\mathrm{P}}$ values of 17 and $26 \mathrm{mJm}^{-2}$ the nylon 6,6 gave rise to less cytotoxicity and to some extent a more enhanced cell response (see Section 12.3 and Section 12.4). It can also be seen from Figure 12.39(b) and Figure 12.41(b) that the correlation between the cytotoxicity, $\theta$ and $\gamma^{\mathrm{P}}$ were the inverse of one another further highlighting the link between $\theta$ and $\gamma^{\mathrm{P}}$ as determined in Chapter 10 .

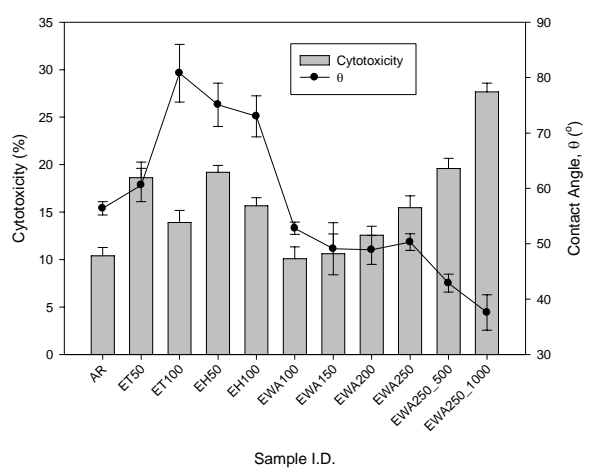

(a)

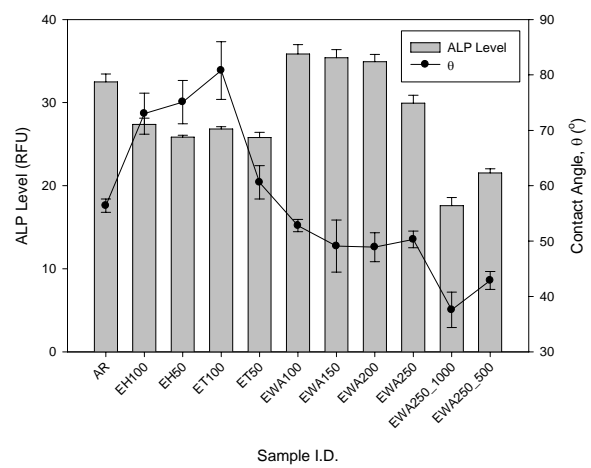

(b)

Figure 12.40 - Histogram showing (a) the ALP level and (b) the cytotoxicity in relation to $\theta$ for all $\mathrm{KrF}$ excimer laser processed samples

\section{Generic Wettability Characteristics that Determine the Biomimetic Nature of Nylon 6,6}

By taking into account the effects of $\theta$ on the osteoblast cell response following $24 \mathrm{hrs}$ incubation, it can be seen that the data plotted in Figure 12.16(a) and Figure 12.16(b) suggest a possible threshold window for $\theta$ between 47 and $53^{\circ}$ which gave rise to an enhanced osteoblast cell response in terms of cell cover density. On the other hand, this also indicates that above or below this $\theta$ threshold window the osteoblast cell response would inherently be hindered slowing the cell proliferation and reducing the cell cover density. The proposed $\theta$ threshold window for the cell cover density can be further identified in Figure 12.16(b) such that for sample EWA250_500 and sample EWA250_1000 with the lowest $\bar{\theta}$ of around $40^{\circ}$ the cell cover density had reduced to around $15 \%$. Also, for the $\mathrm{KrF}$ excimer laser-induced patterned samples which gave rise to the largest $\theta$ of approximately 70 to $80^{\circ}$ it can be seen from Figure 12.16 (b) that the cell cover density reduced to around $18 \%$. These two reductions in cell cover densities are significant when compared to the other samples with $\theta$ between 47 and $53^{\circ}$ because these samples gave rise to the largest cell cover densities of $25 \%$ or more allowing one to extrapolate that a $\theta$ threshold window is possible.

The likelihood of this threshold window is further confirmed using Figure 12.17(a) and Figure 12.17(b) which shows that there could be a $\gamma^{\mathrm{P}}$ threshold window (see Figure 12.15(a)) of 17 to $25 \mathrm{mJm}^{-2}$ which would give rise to an enhanced osteoblast cell response in terms of cell cover density. It should also be noted here that the results shown in Figure 12.17 are mostly the inverse to what was observed with $\theta$ (see Figure 12.16) which can be attributed to the relationship 
between $\gamma^{\mathrm{P}}$ and $\theta$, as determined in Chapter 10. From this the inverse relationship for the two parameters with the cell cover density further attests to the relationship between $\theta$ and $\gamma^{\mathrm{P}}$.

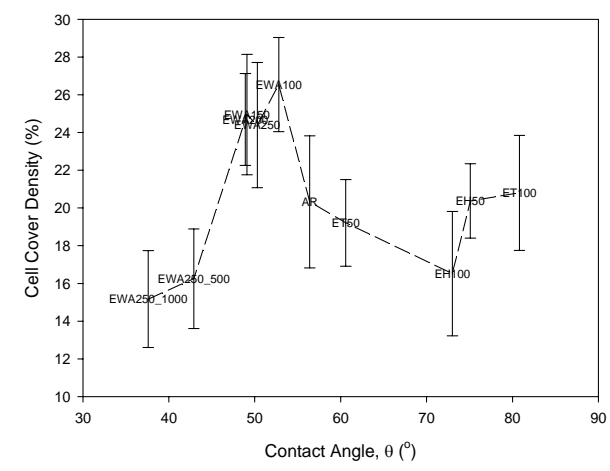

(a)

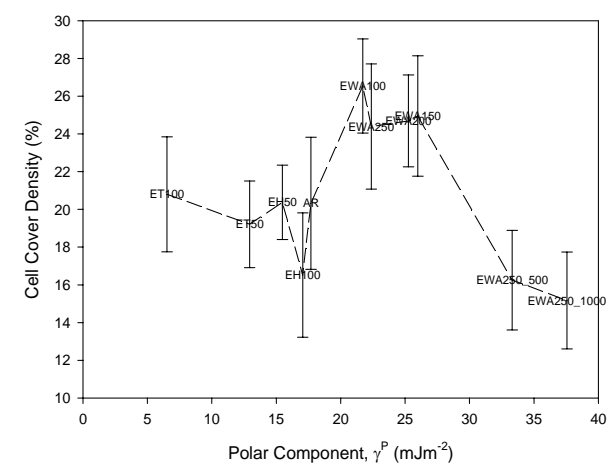

(b)

Figure 12.41 - Graph showing the relationship between cell cover density, (a) $\theta$ and (b) $\gamma^{\mathrm{P}}$ for all $\mathrm{KrF}$ excimer laser processed samples after $24 \mathrm{hrs}$ incubation.

Figure 12.39(a) shows the cytotoxicity levels for each sample in relation to $\theta$. From this it can be seen that a significant reduction of around $20^{\circ}$ in $\theta$ compared to the as-received sample (AR) gave rise to the largest increase in cytotoxicity of approximately $30 \%$ for the $\mathrm{KrF}$ excimer laser whole area irradiative processed samples. This could be highly significant in terms of searching for a threshold parameter to predict how osteoblast cells will react when in a biological environment as this suggests that, for the $\mathrm{KrF}$ laser whole area irradiative processed samples, a large increase in cytotoxicity occurred with $\theta<50^{\circ}$. In fact, the largest reduction in $\theta$ was observed for sample EWA250_1000 which had a $\theta$ of $37.6^{\circ}$ and a cytotoxicity level of $28 \%$. Another factor that may have contributed to this increase in cytotoxicity is that the fluence implemented in this instance was $90 \mathrm{mJcm}^{-}$ 2 and 1000 pulses were used. This could potentially have given rise to noteworthy surface modifications in terms of surface chemistry allowing the sample to become more toxic which has previously been discussed in Section 11.5, inherently allowing for the increase in cell death. In addition to this, it should be noted that most of the $\mathrm{KrF}$ excimer laser processed samples gave rise to an increase in cytotoxicity when compared to the as-received sample (AR). The least increase in cytotoxicity is attributed to the sample EWA100 and sample EWA150 which can be explained by the fact that the fluences used in this instance may not have been high enough to modify either the surface chemistry or surface topography of the nylon 6,6 samples. As a result of this, one observes that the cytotoxicity levels for these samples are equivalent to the as-received sample (AR) which had a cytotoxicity of around $10 \%$. The trend for the $\mathrm{KrF}$ excimer laser whole area irradiative processed samples can also be identified using Figure 12.39(b) showing that the cytotoxicity appeared to have a strong correlation with $\theta$ in that the cytotoxicity was a decreasing function of $\theta$. This trend corresponds with what was observed throughout Section 12.3 and Section 12.4 which identified that the osteoblast cell response was hindered with $\theta$ less than $50^{\circ}$.

Figure 12.39(a) and Figure 12.39(b) also show that for the $\mathrm{KrF}$ excimer laser-induced patterned nylon 6,6 samples there did not appear to be any correlation with what was observed for the $\mathrm{KrF}$ excimer laser whole area irradiative processed samples. This can be attributed to the likely transition in wetting regime, discussed in Chapter 10, having a large impact on varying the results obtained. However, by taking the entire $\mathrm{KrF}$ excimer laser processed samples into account, Figure 12.39(b) allows one to see that there appeared to be an optimum window of $\theta$ for the nylon 6,6 between 47 and $55^{\circ}$ which elicited a reduction in cytotoxicity. This also corresponds with what has been observed in Section 12.3 and Section 12.4. Nevertheless, owing to some erratic results not following any trend for the $\mathrm{KrF}$ excimer laser-induced patterned samples throughout this Chapter, it is necessary for one to realize that these results may not be reliable. Nevertheless, it cannot be ignored that the results on a whole point towards an optimum parameter window for the nylon 6,6 material in terms of osteoblast cell response.

With the modulation of the cytotoxicity levels being observed it is possible for one to deduce that the $\mathrm{KrF}$ excimer laser surface treatments would have a similar effect on the ALP levels. Figure 12.40(a) shows a histogram of the ALP levels in relation to $\theta$. It was 
found from Figure 12.40(a) that sample EWA250_1000 gave rise to the lowest ALP level of 16 RFU which can be attributed to the increase in cytotoxicity and a decrease in $\theta$. In general all of the $\mathrm{KrF}$ excimer laser whole area irradiative processed samples, apart from samples EWA100, EWA150 and EWA200, lead to a reduction in ALP as a result of the increase in cytotoxicity levels. In terms of $\theta$, from Figure 12.40 (b) it can be seen that there appears to be a threshold window of between 47 and $55^{\circ}$ for nylon 6,6 which gives rise to an increased ALP level of between 33 and 40 RFU. That is, any $\theta$ below or above this threshold results in a hindered ALP response. This gives further evidence to the optimum parameter window proposed earlier for the cytotoxicity (see Figure 12.39).

Figure 11.41(a) shows that in general, for the $\mathrm{KrF}$ excimer laser whole area irradiative processed nylon 6,6 samples, the cytotoxicity increased steadily upon an increase in $\gamma^{\mathrm{P}}$. In contrast, a correlative trend between the cytotoxicity and $\gamma^{\mathrm{P}}$ for the $\mathrm{KrF}$ excimer laser-induced patterned samples was not readily discernible from Figure 11.41(a). Having said that, Figure 11.41(b) does show that the cytotoxicity for all of the $\mathrm{KrF}$ excimer laser processed samples could have had a trend with $\gamma^{\mathrm{P}}$ such that between $\gamma^{\mathrm{P}}$ values of 17 and $26 \mathrm{mJm}^{-2}$ the nylon 6,6 gave rise to less cytotoxicity and to some extent a more enhanced cell response (see Section 12.3 and Section 12.4). It can also be seen from Figure 12.39(b) and Figure 12.41(b) that the correlation between the cytotoxicity, $\theta$ and $\gamma^{\mathrm{P}}$ were the inverse of one another further highlighting the link between $\theta$ and $\gamma^{\mathrm{P}}$ as determined in Chapter 10 .

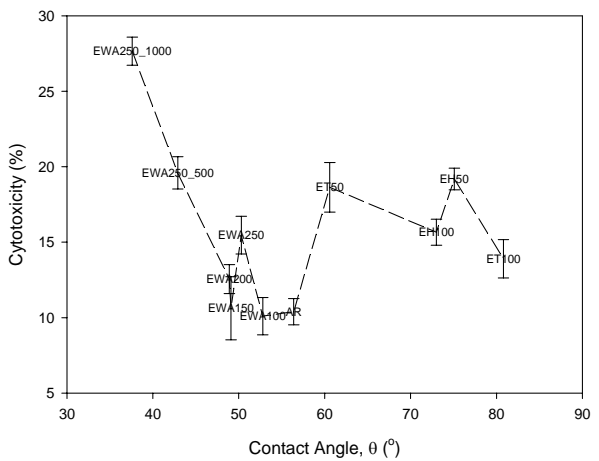

(a)

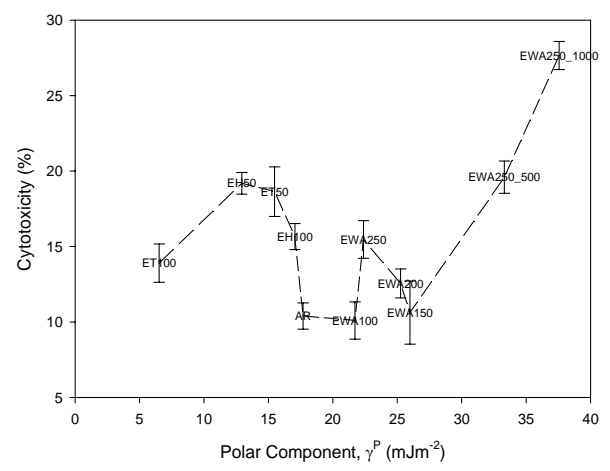

(b)

Figure 12.41 - Graph showing the relationship between cytotoxicity, (a) $\theta$ and (b) $\gamma^{\mathrm{P}}$ for all $\mathrm{KrF}$ excimer laser processed samples after two days incubation.

The relationship between the ALP level and $\theta$ was determined to be the inverse of what was observed between the cytotoxicity and $\theta$ owed to the account that the cytotoxicity and ALP levels are closely linked. From Figure 12.46(a) and Figure 12.46(b) it can be seen that in terms of the relationship between ALP levels and $\gamma^{P}$, this was no different. This is owed to the account that Figure 12.46(b) shows a similar threshold operating window for $\gamma^{\mathrm{P}}$ between 17 and $27 \mathrm{mJm}^{-2}$ which gave rise to the largest increase in ALP levels of approximately 35 RFU. Also, Figure 12.46(a) and Figure 12.46(b) show that for the largest increases in $\gamma^{\mathrm{P}}$ gave rise to the lowest ALP levels further indicating that a more hydrophilic material compared to the asreceived sample lead to a less enhanced osteoblast cell response. This can be accounted for by the rough, toxic surface giving rise to a more hydrophilic surface, an increase in cytotoxicity which resulted in a hindered ALP level and a hindered osteoblast cell response.

Figure 12.47(a) and Figure 12.47(b) allow one to see that like with $\gamma^{\mathrm{P}}$ the ALP level also showed the inverse for $\gamma^{\mathrm{T}}$ as to what was observed with the cytotoxicity and $\gamma^{\mathrm{T}}$ (see Figure 12.42). In addition to this, the ALP levels shown in Figure 12.47(b) give further evidence of an operating threshold window for $\gamma^{\mathrm{T}}$ of between 47 and $53 \mathrm{mJm}^{-2}$ which elicited the highest ALP levels and enhanced osteoblast cell response (see Section 12.3 and Section 12.4). Furthermore, Figure 12.47(a) and Figure 12.47(b) further indicate that an increase in $\gamma^{\mathrm{T}}$, with the nylon 6,6 becoming more hydrophilic, gave rise to a less enhanced osteoblast cell response. As discussed previously for $\gamma^{\mathrm{P}}$, this can be explained by the surface parameters giving rise to a more hydrophilic toxic surface leading to hindered osteoblast cell growth. 


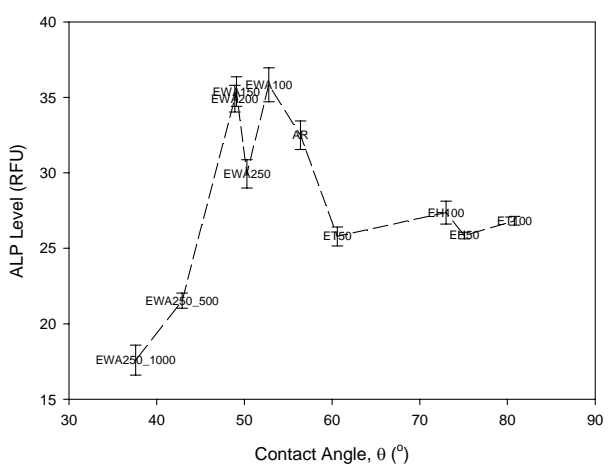

(a)

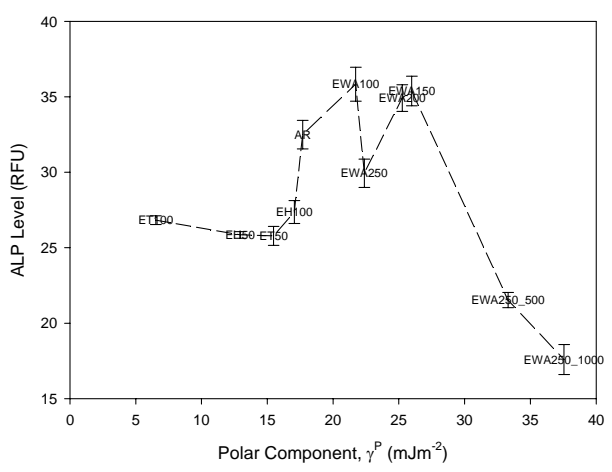

(b)

Figure 12.41 -Graph showing the relationship between ALP Level, (a) $\theta$ and (b) $\gamma^{\mathrm{P}}$ for all $\mathrm{KrF}$ excimer laser processed samples after two days incubation.

It has been seen in Sections 12.3, 12.4 and 12.5 that the $\mathrm{KrF}$ laser surface treatment implemented has given rise to a modulation in osteoblast cell response in terms of cell cover density (see Section 12.3), cell count (see Section 12.4), cytotoxicity (see Section 12.5) and ALP levels (see Section 12.5). Even so, it has been seen throughout this Chapter that, at some point, the cytotoxicity appeared to dominate the osteoblast cell response in that a large increase in cytotoxicity, especially for sample EWA250_500 and sample EWA250_1000, hindered the osteoblast cell response. Figure 12.51(a) shows a histogram of the cytotoxicity for each of the $\mathrm{KrF}$ excimer laser processed samples in relation to the cell count and ALP level. In both instances it can be seen from Figure 12.51(a) that, in general, the cell count and ALP level reduces on account of an increase in cytotoxicity. In fact, that highest ALP levels and cell counts were determined for those samples with the lowest cytotoxicity (Sample EWA100 and sample EWA150); however, it can be seen that these samples had equivalent cytotoxicity levels to the as-received sample (AR) of around 10\% and the cell count can be seen to be significantly low. This is important to note as this indicates that even though the cytotoxicity is low for sample EWA100 and EWA150, other surface parameters will also have an effect on the osteoblast for those samples which have an incident fluence and pulse number below a certain threshold. Above this threshold the cytotoxicity will dominate, ultimately hindering the osteoblast cell growth.

Figure 12.51(b) allows one to see that even though a number of parameters could have played a role in the osteoblast cell response at low fluences and low incident pulse numbers, the cytotoxicity still appeared to play some role in the measured cell count. That is, the cell count reduced on account of an increase in cytotoxicity further suggesting that the $\mathrm{KrF}$ laserinduced cytotoxicity played a significant role in the biomimetic nature of the nylon 6,6 samples.

In a similar means, the ALP level can be seen in Figure 12.51(b) to be a decreasing function of the cytotoxicity for the $\mathrm{KrF}$ excimer laser processed samples. This is a highly important result along with what was observed in Figure 12.51(b) as it allows one to deduce that two common parameters in cytotoxicity and ALP level have been identified which links the osteoblast cell response to a certain extent for both the $\mathrm{KrF}$ excimer laser-induced patterned and $\mathrm{KrF}$ excimer laser whole area irradiative processed nylon 6,6. On account of this, it can be seen that even though different wetting regimes can explain the difference in trends between the osteoblast cell response and surface parameters, the laser-induced cytotoxicity and resulting ALP levels have the major potential in being able to be implemented to predict the biomimetic nature of $\mathrm{KrF}$ excimer laser processed nylon 6,6.

\section{Conclusions}

\section{Acknowledgements}

The authors would like to thank their collaborators: Directed Light Inc., East Midlands NHS Innovation Hub, Nobel Biocare and Photomachining Inc. for all of their much appreciated support. The authors greatly acknowledge the Access to Research Equipment Initiative funded by the EPSRC (EP/F019823/1) and would like to thank Chemical Engineering, Loughborough University for use of their biological laboratory. This study is also financially supported by the EPSRC (EP/E046851/1). 


\section{References}

1. Hao L, Lawrence J. Laser surface treatment of bioimplant materials. New Jersey, USA: John Wiley \& Sons Inc., 2005.

2. Zhao Qea. Evaluation of bacterial adhesion on Sidoped diamond-like carbon films. Applied Surface Science 2007;253:7254.

3. Lawrence Jea. on the correlation between Nd:YAG laser-induced wettability characteristics modification and osteoblast cell bioactivity on a titanium alloy. Surface and Coatings Technology 2006;200:5581.

4. Williams DF. On the mechanisms of biocompatibility. Biomaterials 2008;29:2941-2953.

5. Fauran-Clavel MJ, Oustrin J. Alkaline Phosphatase and Bone Calcium Parameters. Bone 1986;7:95-99.

6. Arefi-Khonsari Fea. Processing of Polymers by Plasma Technologies. Surface and Coatings Technology 2005;200:14.

7. Dadbin S. Surface Modification of LDPE Film by $\mathrm{CO}_{2}$ Pulsed Laser Irradiation. European Polymer Journal 2002;38:2489.

8. Wochnowski Cea. Femtosecond-Laser-Assisted Wet Chemical Etching of Polymer Materials. Journal of Applied Polymer Science 2006;100:1229.

9. Rance DG. Chapter 6 - thermodynamics of wetting: From its molecular basis to technological application.
In: Brewis DM, editor. Surface Analysis and Pretreatment of Plastics and MetalsEssex, UK: Applied Science Publishers, 1982. p. 121.

10. Wu X, Zheng L, Wu D. Fabrication of superhydrophobic surfaces from microstructured $\mathrm{ZnO}$ based surfaces via a wet-chemical route. Langmuir 2005;21:2667.

11. Lee SM, Kwon TH. Effects of intrinsic hydrophobicity on wettability of polymer replicas of a superhydrophobic lotus leaf. J Micromech Microeng 2007;17:687.

12. Chen X, Lu T. The apparent state of droplets on a rough surface. Sci China Ser G-Phys Mech Astron 2009;52:233-238.

13. Cheng, Y. T. et al. Effects of Micro- and NanoStructures on the Self-Cleaning Behaviour of Lotus Leaves. Nanotechnology 2006;17:1359.

\section{Meet The Author}

David Waugh is currently undertaking a Ph.D. at the Wolfson School of Mechanical and Manufacturing Engineering, Loughborough University, UK under the supervision of Dr. Jonathan Lawrence. His research is focusing on using laser surface treatment of polymeric biomaterials for enhanced cell response. He obtained his MPhys Hons. in Physics with Lasers and Photonics and MSc in Laser Applications in Micro-Machining and Processing from the University of Hull, UK. 